Wilfrid Laurier University

Scholars Commons @ Laurier

\title{
Perceiving and responding to the Personal/group discrimination discrepancy
}

\author{
Mindi D. Foster \\ Wilfrid Laurier University, mfoster@wlu.ca \\ Kimberley Matheson \\ Carleton University, kim.matheson@carleton.ca
}

Follow this and additional works at: https://scholars.wlu.ca/psyc_faculty

Part of the Psychiatry and Psychology Commons, and the Social Psychology Commons

\section{Recommended Citation}

Foster, Mindi D. and Matheson, Kimberley, "Perceiving and responding to the Personal/group discrimination discrepancy" (1999). Psychology Faculty Publications. 41.

https://scholars.wlu.ca/psyc_faculty/41

This Article is brought to you for free and open access by the Psychology at Scholars Commons @ Laurier. It has been accepted for inclusion in Psychology Faculty Publications by an authorized administrator of Scholars Commons@Laurier. For more information, please contact scholarscommons@wlu.ca. 
Running head: Personal/group discrimination discrepancy

Perceiving and responding to the

Personal/group discrimination discrepancy

Mindi D. Foster

University of North Dakota

Kimberly Matheson

Carleton University, Ottawa, Canada

\begin{abstract}
To explain why minority group members recognize less personal than group discrimination, research has focused on cognitive processes. While within self-categorization theory it may be argued the discrepancy is a function of a salient social self that perceptually discounts the personal self, it can also be argued that depersonalization allows for the cognitive possibility of perceiving similar amounts of personal and group discrimination. The present study suggested that, consistent with group consciousness theories, the social self may serve to both discount as well as integrate the social self, depending on the way in which the social self is defined. Using structural equation modeling, the present study found that defining the social self along social experiences was associated with lower personal/group discrimination discrepancy scores which in turn were associated with greater participation in collective action. Implications for different definitions of the social self were discussed.
\end{abstract}

Perceiving and responding to the personal/group discrimination discrepancy

In 1948, when Israel's political right to exist as a nation was established, Jewish families in North America and Europe began to feel safe. Previously, the history of the Jewish people had entailed having to make the choice between relinquishing their religion or being expelled from their own 
countries. Therefore, Israel represented a "safe haven" where individual Jews in the diaspora would always be guaranteed their religious freedom if history were to repeat itself.

In 1989, when Marc Lepine killed 14 women in Montreal, the danger that exists in the context of women's everyday lives was heightened. While violence against women had always existed, it seemed closer than ever when Lepine's target for feminists entered a university campus. It made many women more aware that they too were personally vulnerable to violence in the simple conduct of their daily activities.

While these groups appear to have undergone different experiences, namely feelings of safety versus fear, both situations exemplify groups that have recognized how the politics of the group can affect the individual's daily experiences. In other words, individual group members recognized that they may suffer personal discrimination as a function of their group membership.

Most often however, it appears as if minority group members are expressing the opinion that discrimination may affect "them, but not me". This robust tendency to recognize group but not personal discrimination has been labelled the "personal/group discrimination discrepancy" (Taylor, Wright, Moghaddam \& Lalonde, 1990) and has been found consistently in working women in the United States (Crosby, 1982, 1984) and Canada (Hafer \& Olson, 1993; Ruggiero \& Taylor, 1994); university women (Foster \& Matheson, 1995; Porter \& Taylor, 1992; Ruggiero \& Taylor, 1995); Canadian immigrants (Taylor et al., 1990) and ethnic groups (Dion \& Kawakami, 1996); lesbian women (Crosby Pufall, Snyder, O'Connell \& Whalen, 1989); gay men (Birt \& Dion, 1987; D'Emilio, 1983); African American men, Aboriginal peoples (Taylor, Wright \& Porter, 1994) and Canadian Francophones (Guimond \& Dubé-Simard, 1983).

Given the robustness of the personal/group discrimination discrepancy, researchers have focused on the possibility that the discrepancy may be a function of the way in which humans generally process information. For 
instance, Ruggiero and Taylor (1994) found that university and working women generated more examples of group than personal discrimination.

Crosby et al. (1986) found that women recognized more severe discrimination when data about job discrimination in a company was presented to them in a grouped (information regarding sex discrimination in several departments was presented simultaneously on one page) rather than an individualized (information about each department was presented on separate pages) format. Recently, Moghaddam, Stolkin and Hutcheson (1997) found that individuals perceive even positive events as affecting their group more than themselves. Together, these studies suggest that information about the group may be more salient or more easily processed than information based on an individual's experience. Indeed, the Gestalt laws of pattern perception (e.g., Biederman, Hilton \& Hummel, 1991) whereby humans tend to recognize patterns of stimuli rather than individual stimuli have long supported the notion that humans may have a perceptual preference for group rather than individualbased information. Thus, research has concentrated on explaining the personal/group discrimination discrepancy primarily as a cognitive bias toward perceiving group-based experiences.

Some would argue that the cognitive bias explanation of the personal/group discrimination discrepancy is consistent with self-categorization theory (Turner, Hogg, Oakes, Reicher \& Wetherell, 1987) which explicitly discusses the cognitive basis of intergroup behavior. While self-categorization theory is a broad attempt to explain a wide range of intergroup phenomenon, there is a particular set of assumptions and hypotheses regarding the ways in which people categorize themselves that may aid in understanding why the personal/group discrimination discrepancy occurs. First, the theory delineates ways in which people categorize themselves, in particular as individuals and as group members. On an individual level, the theory refers to a "personal self-categorization" which involves an individual's sense of her/himself as unique. On a group level, the theory refers to a "social self-categorization" which involves people's sense of themselves as a group member. 
Second, the theory proposes that these self-categorizations are made salient through the process of social comparison. The individual's sense of her/himself as unique becomes salient in a context involving comparisons between the self and the ingroup. In contrast, social self-categorizations become salient when people are in a context involving comparisons between the ingroup and an outgroup.

When a social self-categorization is salient, it is reflected by a particular pattern of perceptions referred to as a high "meta-contrast ratio". A metacontrast ratio is defined as the ratio of the perceived differences between members of one category and another, to the perceived differences among members within one category (Turner, et al.,1987). The meta-contrast ratio is high if "between group differences" are perceived to be greater than "within group differences". For example, a woman whose self-categorization as a woman is salient will perceive the differences between men and women to be larger than differences among women.

Given the bipolar nature of similarities and differences, that is the more a stimulus is considered similar to others in a category the less it is considered unique (Bruner, 1957, Campbell, 1958, Rosch, 1978, Tajfel, 1969), the theory further suggests there is "an inverse relationship between the salience of the personal and social levels of the self-categorization" (Turner et al., 1987, p.49). A person cannot cognitively view themselves as unique and as a group member at the same time. Thus, when a social self-categorization is salient, a personal self-categorization is "perceptually discounted". Indeed, there is support for this inverse relationship in that when a personal self is salient via ingroup comparisons, minority group members take actions to enhance their individual status rather than group actions, and when a social self is salient via intergroup comparisons, they are more likely to take actions to enhance the group status rather than individual actions (Hafer \& Olson, 1993; Kawakami $\&$ Dion, 1993). Thus it appears that when one level of the self-categorization is salient, the other is perceptually discounted.

This process of perceptual discounting has implications for perceiving group 
versus personal discrimination. In particular, if the salience of the social self results in perceptually discounting the personal self, then personal and group discrimination may not be recognized to the same degree. Indeed, studies of the personal/group discrimination discrepancy assess both group (e.g., women are discriminated against in relation to men) and personal (e.g., I am discriminated against in relation to men) discrimination using outgroup comparisons (e.g., Crosby, 1984; Taylor et al., 1990). As such, a social selfcategorization should become uniquely salient and a woman's experiences will be processed at the group level alone, allowing for easier recognition of group discrimination. Because a social self-categorization presumably discounts the personal self-categorization however, a woman will not be processing information on an individual level, and therefore will be unlikely to recognize personal discrimination. Thus a discrepancy between personal and group discrimination is maintained. Empirically, the robustness of the personal/group discrimination discrepancy despite a salient social identity suggests that the discrepancy may indeed be a cognitive bias such that a salient social self discounts perceptions of personal discrimination (Crosby et al., 1989; Porter \& Taylor, 1992).

At the same time however, self-categorization theory also refers to the notion of "depersonalization" which occurs when an individuals' social self becomes salient to such an extent that they view themselves as an “interchangeable exemplar" of their ingroup (Turner et al., 1987, p. 50). In other words, the individual is her/his group. This reflects an integration of the personal and social self-categorization (Turner et al., 1987), rather than personal and social selves that are inversely related. Empirically, depersonalization is also supported by Smith and Henry (1996) who found that reaction times to trait self-descriptions were quicker when these traits also described the ingroup rather than the outgroup, suggesting that individual descriptions can encompass social elements. In relation to intergroup behavior, women have been shown to participate in more collective action when they perceived both group and personal discrimination than when they 
perceived personal discrimination alone (Foster \& Matheson, 1995). Taken together, these studies suggest the social and personal selves might indeed be integrated. The implication for a social self that has integrated the personal self may be that similar, rather than discrepant assessments of both personal and group discrimination could potentially be made. If the personal self has become depersonalized such that a woman sees herself as a group member rather than a unique individual, then presumably whatever happens to the group has happened or could happen to her. Under these circumstances, the perceived discrepancy between personal and group discrimination would decrease. Thus, self-categorization theory (Turner et al., 1987) appears to allow for two roles of a salient social self, both having different implications for the magnitude of the personal/group discrimination discrepancy. On the one hand, it may be argued the discrepancy is a function of a cognitive bias such that a salient social self discounts the perception of personal discrimination (Crosby et al., 1986; Hafer \& Olson, 1993; Kawakami \& Dion, 1993 ; Moghaddam et al., 1997; Ruggiero \& Taylor, 1994). On the other hand, it may also be argued that depersonalization allows for the cognitive possibility of corresponding amounts of personal and group discrimination (Foster \& Matheson, 1995; Smith \& Henry, 1996).

While the notion of depersonalization suggests there should be no discrepancy between perceived personal and group discrimination, the robustness of the personal/group discrimination discrepancy (e.g., Crosby, 1984; Dion \& Kawakami, 1996; Hafer \& Olson, 1993; Taylor et al., 1990) implies that an integration of the social and personal self does not occur.

However, this may be an artifact of how the social self is defined. Typically, a social self-categorization has been operationally defined as a high meta-contrast ratio, which is described as occurring along the "stereotypical dimensions which define the relevant ingroup membership" (Turner, et al., 1987, p. 50). Stereotyped traits are commonly used to reflect the dimensions along which to measure the meta-contrast ratio because of their presumed relevance to definitions of the group (Hogg \& Turner, 1987; Lee, 
1992; Oakes \& Turner, 1990; Stephan, 1977; Turner, et al., 1987; Turner \& Oakes, 1986,1989; Turner, Oakes, Haslam, \& McGarty, 1994). For example, a woman's social self-categorization is said to be salient when she perceives differences between men and women to be larger than differences among women in terms of their tendency to be "emotional" or "sensitive". Thus, minority group members's social identities are often operationally defined along intrinsic, stereotyped traits.

However, if minority group members are defining themselves in terms of intrinsic personality characteristics, then when they are asked to assess situations of discrimination, they may also make internal attributions for a situation they personally experience rather than defining it as stemming from group-based discrimination. Consider a young woman who has just been told by her college guidance counselor that she should consider studying early childhood education rather than science because women tend to excel in those areas. If she defines women along stereotyped traits such as nurturing and as such considers women to have a "nurturing personality", she might internalize this situation, reasoning that as a woman, her personality is better suited to early childhood education than to science. The situation she has just experienced would be therefore be defined as reflecting internal aspects of herself ("it's my personality"). Consequently, when she is asked whether she has experienced personal discrimination due to gender, her response will likely be "no". Thus, defining the social self along intrinsic traits may serve to maintain a distinction between the personal and social self, and as such, a perceived discrepancy between personal and group discrimination.

In contrast, group consciousness (Bartky, 1977, Bowles \& Duelli Klein, 1983 Dreifus, 1973, Wilkinson \& Schneider, 1990) and new social movement theories (Friedman \& McAdam, 1992; Gamson, 1992) are based on the grassroots experiences of minority groups attempting to challenge traditional definitions of their group. These theories define the social self as being integrated with the personal self rather than being inversely related, telling women that the "personal is political" (Carey, 1980, Dreifus, 1973, Stanley \& 
Wise, 1983, Wilkinson \& Schneider, 1990). Women were encouraged to make this connection between the person and the group in the feminist consciousness-raising groups of the 1970s (e.g., Carey, 1980; Dreifus, 1973). These groups encouraged women to share their experiences and in so doing they discussed various issues such as abuse from husbands, rape and verbal assaults, the meanings of femininity and sexuality, lack of work, lack of respect at work, being secretaries, mothers, and husbands' maids and cooks. As women shared their experiences it became more apparent that many other women had encountered similar incidents and that the individual woman was "not the only one". In essence, they were recognizing similarities among women and differences between women and men, or a high meta-contrast ratio along social experiences that stemmed from factors outside of the individual.

By defining women along shared social experiences rather than intrinsic traits, a personal experience of group-based discrimination may be defined as such, rather than internalized. Consider again the woman who is told by her guidance counsellor that she should consider early child education programs rather than science in college. By defining women in terms of shared social experiences (e.g., "women as a group who experience limited educational opportunities") she may externalize this situation, reasoning that her counselor's advice was an example of how women are discriminated against in the education system, as opposed to being an accurate reflection of her "nurturing personality". In turn, by making an external attribution for this experience, when she is asked whether she has experienced personal discrimination due to gender, she will likely respond "yes". Thus, the examination of alternative theories of group identity (group consciousness) suggests that by defining the social self differently (along external social experiences rather than internal stereotyped traits) there may indeed be an integration of the personal and social selves, which may decrease the perceived discrepancy between personal and group discrimination.

Not only do group consciousness theories describe the antecedents of a reduced personal/group discrimination discrepancy, but they also refer to the 
consequences. Specifically, collective action is presumably most likely when the individual and group experiences have become integrated. For example, the slogan "personal is political" served as motivation for collective action in the 1970s (Carey, 1980; Dreifus, 1973). The more individual women believed their personal experiences were integrated with the group's, the more the group's problem (discrimination) became personally relevant. As the group problem became more relevant, the solution (collective action) also became viewed as important for the individual's status. Thus, according to group consciousness theories, a reduced personal/group discrepancy should be associated with greater collective action.

This is consistent with s elf-categorization theory (Turner et al., 1987) which predicts that all group behavior, including collective action is a function of depersonalization. Once individuals view themselves as an interchangeable exemplar of their group, their actions are directed at enhancing the group rather than themselves. As such, greater collective action should occur. Little research has been done however on the relationship between the personal/group discrimination discrepancy and intergroup behavior. Most research on the discrepancy focuses on its explanations (e.g.,Moghaddam et al., 1997). Further, research that does examine antecedents for collective action (e.g., relative deprivation theory) has traditionally focused on perceptions of group discrimination alone, ignoring the notion of an integrated personal and social self as motivation for action (e.g., Guimond \& DubéSimard, 1983; Walker \& Mann, 1987; Walker \& Pettigrew, 1984).

The present study was therefore conducted to examine possible antecedents and consequences of perceiving the personal/group discrimination discrepancy. It was hypothesized that a social self-categorization defined along intrinsic traits may serve to maintain a distinction between the experiences of personal and social selves, maintaining the perceived discrepancy between personal and group discrimination. In contrast, a social self defined along external experiences may serve to integrate the experiences of personal and social selves, reducing the perceived discrepancy between 
personal and group discrimination. Consistent with both group consciousness (eg., Bartky, 1973) and self-categorization theories (Turner et al., 1987), a reduced personal/group discrimination discrepancy may be associated with greater collective action.

\section{Method}

\section{Participants and Procedure}

Women in an Introductory Psychology course at Carleton University who had indicated a willingness to participate in a study to partially fulfil their course requirement were telephoned. They were asked if they would complete a 45-minute questionnaire 1 which would be given at Carleton University. Questionnaires were completed in groups of 5-15 $(\underline{\mathrm{N}}=141$; Mean age $=22.0$; range 18-55). Once the questionnaires were completed, students were given an oral and written debriefing regarding the purpose of the study.

\section{Materials}

\section{Meta-contrast ratios.}

Participants first indicated their perceptions of ingroup and intergroup variability by rating how similar women are to each other and how similar women and men 2 are along five social experiences (being paid less than men for equal work; feeling unsafe (e.g., walking along after dark); having to work harder than men to get ahead; having fewer career opportunities than men; experience with sexual harassment) and six stereotyped traits (nurturing; emotional; sensitive; yielding; understanding; and childlike) 3 . Responses were assessed along a scale ranging from "not at all similar" (0) to "extremely similar" (4).

In order to compute the meta-contrast ratios for each item, scores on both measures of ingroup and intergroup variability were then recoded such that higher scores reflected higher perceptions of ingroup and intergroup differences (Turner et al., 1987). These scores were then transformed by adding a constant of 1 , in order to avoid any division by zero in the calculation 
of meta-contrast ratios. From these scores, a meta-contrast ratio was computed by dividing perceptions of intergroup differences by perceptions of ingroup differences. Scores could range from 0.2 to 5.00. Meta-contrast ratios greater than 1 represented greater perceived intergroup than ingroup differences, or in other words, a salient social identity along a particular (Turner et al., 1987).

\section{Personal/group discrimination discrepancy. In order to assess the} personal/group discrimination discrepancy, "discrepancy scores" (Chaiken \& Baldwin, 1981; Taylor et al., 1994) were computed from participants' perceptions of personal and group discrimination along the same five experiences that were used to assess the meta-contrast ratios along social experiences. In particular, participants were asked to indicate how much personal and group discrimination they perceived in terms of "receiving less pay for the same jobs as men"; "having to face greater threat to their personal safety on a day to day basis"; "having to work harder than men to get the same recognition"; "not receiving the same career opportunities as men"; "being victims of sexual harassment". Responses were assessed along a scale ranging from "not at all discriminated against" (0) to "extremely discriminated against" (4).

To compute the discrepancy scores, participants' personal discrimination score was subtracted from their group discrimination score for each dimension. Thus, five discrepancy scores were computed. Higher scores reflected larger personal/group discrimination discrepancies, or in other words, the perception that group relative to personal discrimination was high.

Collective action. Based on a scale from Foster and Matheson (1995), participants indicated on a scale ranging from 0 (never participate) to 4 (always participate) how often they participate in a list of six actions geared at enhancing women's status, during their everyday life. Collective action was defined as any behavior directed at enhancing the group status (Wright, Taylor \& Moghaddam, 1990). Behaviors included private actions such as "I have gone out of my way to collect information on women's issues," as well as 
increasingly more public actions such as "I encourage friends to join organizations that deal with women's issues"; "I talk about women's issues with family or friends, stressing the need to enhance women's positions in society"; "I attend talks on women's issues", "Whenever there is an organized protest, I attend the protest", "I participate in fundraisers, consciousnessraising events etc. that attempt to increase the overall status of women". The list of actions was originally derived from Lalonde and Cameron (1993) but was reworded to maintain context specificity for women.

\section{Results}

\section{Descriptive Statistics}

To examine the nature of women's definitions of their social selves, means and standard deviations for the variables in the model were calculated (see Table 1). In particular, it appears that all but one meta-contrast ratio (childlike) was greater than one, indicating that women overall appeared to view women as similar to each other but different from men in terms of both stereotypes and social experiences. Because the childlike meta-contrast ratio was not significantly different from $1, \mathrm{t}(139)=-.78, \mathrm{~ns}$, it was retained.

Consistent with past research, women reported greater group than personal discrimination in terms of pay equity, personal safety, having to work harder than men, fewer career opportunities and sexual harassment. While the mean differences were small, effect sizes ranged from $14 \%$ to $39 \%$, indicating meaningful differences (see Table 1).

Finally, women tended to participate in collective actions relatively frequently in their lives $(\underline{\mathrm{M}}=2.72, \underline{\mathrm{SD}}=.93)$.

\section{$\underline{\text { Structural Model }}$}

The analysis was performed on a reduced sample size of 117 women who reported perceiving group discrimination. Group discrimination was measured by taking a mean score across the five group discrimination items . Women who reported little or no group discrimination (i.e., those who scored 
below the midpoint, 2) were eliminated from the sample to ensure that the conceptual and operational definitions of the personal/group discrimination discrepancy matched. While it is possible that a discrepancy could exist between perceiving little group discrimination and even less personal discrimination, the construct has been theoretically defined as recognizing that discrimination happens to one's group, but not to oneself (Crosby, 1984). Therefore, to remain theoretically consistent, only women who reported recognizing group discrimination were included in the analysis.

Structural equation modelling, which tests hypotheses about patterns of relationships among latent variables, was used to assess the multivariate relationships between the meta-contrast ratios along social experiences and stereotypes, as well between the personal/group discrimination discrepancy and collective action. Assessment of fit of the measurement models, as well as the structural equation model, was based on several indices. Although the $\chi^{2}$ statistic tests how well the hypothesized model data fits the observed data, it does not tend to be accurate in small samples (Bentler \& Bonnet, 1980; Byrne, 1989). Thus, researchers suggest that the $\chi 2$ be reported, but that it not be used as the primary index of goodness of fit (Hoyle \& Panter, 1995; Hu \& Bentler, 1995).

Instead, alternative indices of fit are utilized in structural equation modelling. First, the average off-diagonal residuals were examined, which represent the average amount of correlation between the hypothesized and observed data that is unexplained by the model. If residuals are small, the model is considered to exhibit good fit of the data (Hu \& Bentler, 1995). A second criterion is the Comparative Fit Index (CFI; Bentler, 1990) which ranges from 0 to 1.00 , with .90 ore greater indicating adequate fit of the data (Byrne, 1994; Hoyle \& Panter, 1995; Hu \& Bentler, 1995). A third criterion is the Parsimony Comparative Fit Index (PCFI; Mulaik, James, Van Alstine, Bennett, Lind, \& Stilwell, 1989), which takes into account degrees of freedom. Because high CFI values can occur due to low degrees of freedom, the PCFI compensates for this problem. Values of .50 accompanying CFI values of .90, 
have been considered acceptable fit of the data (Mulaik et al., 1989), and recently values of .80 are considered to be better fit of the data (see Byrne, 1994). Finally, the root mean square error of approximation (RMSEA) represents the amount of error in approximating the population data by the sample data. Values of less than .05 are considered to reflect close fit of the data, values between .05 and .08 reflect moderate fit of the data, and values above .1 reflect poor fit of the data (Browne \& Cudeck, 1993; MacCallum, Browne $\&$ Sugawara, 1996). The RMSEA also provides a $90 \%$ confidence interval for the value. While all indices are generally considered, research suggests that when there is a dispute between the indices, the residuals are the most reliable (Byrne, 1991; Hu \& Bentler, 1995). All models (see Table 2) were assessed using EQS, a statistical package designed to test structural models (Bentler \& Wu, 1995). Maximum likelihood estimation, with the Satorra-Bentler Scaled Statistic correction was used due to small sample size (Byrne, 1994; Hu \& Bentler, 1995).

The first step in testing the model was to ensure that the measurement models, that is, the variables measuring each of the four latent variables adequately measured the factors they were designed to assess (Byrne, 1989). Thus, confirmatory factor analyses were performed to assess the fit for each latent variable (meta-contrast ratio along social issues and stereotypes, the personal/group discrimination discrepancy and collective action). These measurement models were specified such that each factor could be explained by the indicator variables designed to measure it, and the error terms would be uncorrelated.

As Table 2 indicates, all indices for the measurement models suggested that each of the variables were good estimates of the latent variables they were designed to measure 4 . In particular, the $X 2$ values were non-significant, suggesting no significant differences between the observed and hypothesized data. The CFI values ranged between .96 and .99 , indicating very good fit of the data, and PCFI values are consistent with these high CFI values. While the RMSEA values for stereotypes and collective action were close to .1 
(indicating poor fit of the data), the rest of the indices imply good fit of the data. Given the dispute, the small residuals were relied upon, suggesting good fit of the data for all the measurement models (e.g., Hu \& Bentler, 1995).

Given that the measurement models were stable, a structural model was then specified, hypothesizing that larger meta-contrast ratios along stereotypes would be related to larger reported personal/group discrimination discrepancy scores, while smaller meta-contrast ratios along social experiences would be related to smaller reported discrepancy scores, which in turn would be related to greater participation in collective action. As Table 2 indicates, CFI was .92, and the PCFI was high (.82), indicating good fit of the data. The residuals were also small (.07), also indicating good fit of the data, and the RMSEA and its confidence interval suggest acceptable fit of the data. Taken together, these indices suggest the hypothesized model provides good fit of the data.

As hypothesized, the path coefficients indicate that larger meta-contrast ratios along stereotypes were associated with a larger perceived personal/group discrimination discrepancy (See Figure 1). In contrast, larger meta-contrast ratios along social experiences were associated with a smaller perceived personal/group discrimination discrepancy, which was also associated with greater participation in collective action.

\section{Discussion}

To explain why minority group members recognize less personal than group discrimination, psychological research has focused on cognitive processes. While it may be argued the discrepancy is a function of a cognitive bias such that a salient social self discounts the perception of personal discrimination (e.g., Kawakami \& Dion, 1993 ; Moghaddam et al., 1997), it can also be argued that depersonalization allows for the cognitive possibility of perceiving similar amounts of personal and group discrimination (e.g., Smith \& Henry, 1996). The present study suggested there may be ways in which the social self can serve to both discount as well as integrate the social self, depending on the way in which the social self is defined. 
As expected, greater meta-contrast ratios along stereotypes were associated with larger discrepancy scores indicating that the more strongly women defined their group in terms of stereotypes, the greater was their perceived discrepancy between group and personal discrimination. This finding appears to support the process of the cognitive discounting of a personal self by a social self as is suggested by self-categorization theory (Turner et al., 1987). If women are defining the group along intrinsic stereotyped traits, then group-based treatment (discrimination) may be similarly attributed to personal characteristics. While the present study did not measure the extent to which women were internalizing situations of discrimination, past research has found that women's endorsement of traditional stereotypes is related to making internal attributions for their own failures (Neto, 1995) and for experiences of sexual harassment (Jensen \& Gutek, 1982). Thus, when the group is defined along intrinsic stereotyped traits, personal blame for discrimination may be accentuated, which in turn may decrease the recognition that personal experiences of discrimination are instead due to group circumstances. Ironically then, a social self defined along stereotypes may indeed serve to keep the personal and social selves distinct, but not through a "discounted" perception of the personal self. Rather, the personal self may in fact be accentuated in that women may be blaming themselves for experiences that are actually a function of discrimination against their group. Thus, a larger personal/group discrimination discrepancy may be a function of an accentuated sense of the personal self.

In contrast, when the social self was defined along shared external experiences (higher meta-contrast ratios along social issues), women reported a reduced personal/group discrimination discrepancy. Some may argue that the association between defining the group along shared external experiences and the personal/group discrimination discrepancy may have occurred because both latent variables were measured along the similar items. For instance, women rated how similar they thought women were to each other, and different from men in terms of their experience with sexual harassment, and as 
well indicated how much they had experienced sexual harassment. Clearly, the measures of trait-based stereotypes were not so directly linked to the measures of the personal/group discrimination discrepancy. However, the association between the meta-contrast ratio along experiences and the personal/group discrimination discrepancy is not likely due to shared measurement error for two reasons. First, one of the benefits of structural equation modeling is that it indicates measurement error; the present model indicated no significant shared error among the items measuring the metacontrast ratio along social experiences and those assessing the discrepancy. Second, a shared measurement explanation of the relationships between these two latent variables could not account for the direction of the association, which was as hypothesized, negative. Thus, the role that the meta-contrast ratio along social experiences may serve in reducing the personal/group discrimination discrepancy is not likely an artifact of measurement.

Instead, defining the group along social experiences may be one way in which depersonalization occurs. It may be that if women are defining their group identity along external factors, then group-based treatment may be similarly attributed to external sources. If a woman defines her social group along external characteristics, then when she encounters a situation of social discrimination she will likely externalize the blame. Thus, the personal self, in the form of personal blame may actually be discounted. Paradoxically, by discounting personal blame women will recognize greater personal discrimination in relation to group discrimination because they may define personal experiences of discrimination as being due to gender rather than being due to their own characteristics. Personal experience therefore becomes defined as a group experience, or in other words, the personal and social self become integrated.

When the personal and social selves are integrated, self-categorization theory (Turner et al., 1987) suggests any group behavior, including collective action is likely to occur. Similarly, group consciousness (e.g., Wilkinson \& Schneider, 1990) and new social movement theories (e.g., Friedman \& 
McAdam, 1992; Gamson, 1992) would suggest that a reduced personal/group discrimination discrepancy should also encourage collective action. These theories suggest that by recognizing that both group and personal discrimination, women have recognized that "what happens to the group, happens to me", or in other words they have integrated the personal and social experiences. As such, the social group may be more personally relevant, and participation in group-oriented behavior such as collective action may seem more important and worthwhile to enhancing individual status. Consistent with this hypothesis, the present study found that as women reported smaller discrepancies between personal and group discrimination, their participation in collective action increased.

The association between the personal/group discrimination discrepancy and collective action however was small, indicating the need to understand additional variables that may motivate collective action. Certain negative emotions may play an important role in understanding the relationship between the personal/group discrimination discrepancy and taking action. While a reduced discrepancy may make the group experience personally relevant, it may at the same time be anxiety provoking to recognize the extent to which society can impact on the individual (Crosby, 1984). As such, consistent with learned helplessness theories (e.g., Seligman, 1975) the anxiety may reduce instrumental behaviors, attenuating the relationships between recognizing personal discrimination and taking collective action. While feelings of discontent have been found to be associated with reduced participation in collective action (Foster \& Matheson, in press), future research will need to examine how more extreme emotions such as anxiety, as well as ways to relieve that anxiety (e.g., coping strategies, social resources) may mediate the relationship between the personal/group discrimination discrepancy and taking collective action.

Some might also argue that collective action may have been related to the meta-contrast ratios, and as such a mediating model should have been implied and tested. While a mediating model is indeed possible, the present paper did 
not put forth a theoretical rationale that hypothesizes a mediating model. To do that, two hypotheses would have to have been made. First, it would have been hypothesized that there is a relationship between the meta-contrast ratios and collective action. While such a relationship may exist, the primary purpose of the present study was to test the antecedents of the discrepancy (meta-contrast ratios) and the directions of the relationships between the metacontrast ratios and the discrepancy. Thus, a theoretical rationale for an association between the meta-contrast ratios and action was not developed.

The second hypothesis that would need to be made to test a mediating model is that the relationship between the meta-contrast ratios and collective action should disappear when the personal/group discrimination discrepancy is considered. However, we did not want to assume such a relationship should disappear, especially given the consistent relationship between beliefs about a group's lower status and their endorsement of actions to enhance their status (e.g., Foster \& Matheson, 1995; Hafer \& Olson, 1993). For these reasons, a mediating model was neither postulated nor tested in the present study.

Although there was a small association between the personal/group discrimination discrepancy and action, it is an important relationship in that it highlights the need to consider how the social self is being defined and how this in turn affects perceptions of the personal self. Traditionally however, North American society tends to promote a disjunction between the individual and their social group. "Rugged individualism" is valued over depending on others, and this is often reflected in psychological concepts. For instance, maturity is often marked in a North American child when they show independence while immaturity is marked by consulting with others (Kohlberg, 1963). However, as the present study suggests, the less connected individual group members are to their group experience, the less important group change may become. In contrast, whether the connection between the group and the individual is motivated by safety or fear, both Jews in the Diaspora, and women in Canada played a role in social changes such as the economic support of Israel and changes in Canadian gun laws, respectively. 
Thus, by examining theories based in grass-roots experiences of groups trying to alter the status quo, insight may be gained into how a connection between the person and the group can be encouraged, and how this connection is important for social change.

\section{Author Note}

Correspondence should be addressed to Mindi D. Foster, at the Department of Psychology, University of North Dakota. P.O. Box 8380, Grand Forks, North Dakota. 58202-8380. Phone: (701) 777-4496. Email: foster@badlands.nodak.edu.

A portion of this data was presented in poster-format at the 105 th Annual Convention of the American Psychological Association, Chicago, 1997.

\section{Footnotes.}

1. The questionnaire's length was a function of other measures included in the package (used for a different study). They followed those used in the present study.

\section{Consistent with self-categorization theory, meta-contrast ratios are} measured along dimensions relevant to group membership. Thus, in order to ensure the dimensions along which the meta-contrast ratios were assessed would indeed be relevant to women, an independent sample of university women $(\mathrm{N}=75)$ were asked to report in an open-ended format, the types of traits and issues that are relevant to women today (Foster, 1995). Responses were examined for recurring themes in terms of the social experiences that viewed as important to women, and stereotyped traits that were regarded as applicable to women. Thus, all dimensions in the present study had been piloted and reflect dimensions relevant to this sample.

3. Meta-contrast ratios are generally conceptualized in terms of differences between groups, but measured in terms of similarities (e.g., Haslam \& Turner, 1992). Thus, in the present study similarity scores were recoded to reflect differences to remain consistent with the theoretical conceptualization. 
4. Because of space concerns, and given that loadings change once the full model is tested, the loadings for each of the confirmatory factor analyses were not included in this manuscript. However, that information is available from the authors upon request.

\section{References}

Bartky, S. L. (1977) Toward a phenomenology of feminist consciousness. In M. Vetterling-Braggin, F. Elliston, \& J. English (Eds.), Feminism and philosophy. (pp. 22-37). Totawa, NJ: Littlefield.

Bentler, P. M. (1990). Comparative fit indices in structural models. Psychological Bulletin, 107, 238-246.

Bentler, P. M. \& Bonnett, D. G. (1980). Significance tests and goodness-offit in the analysis of covariances structures. Psychological Bulletin, $\underline{88}, 588$ 606.

Bentler, P. M. \& Wu, E. J. C. (1995). EQS for windows user's guide. Encino, CA: Multivariate Software Inc.

Bierderman, I., Hilton, H. J., \& Hummel, J. E. (1991). Pattern goodness and pattern recognition. In G. R. Lockhead \& J. R. Pomerantz (Eds.), The perception of structure (pp. 73-95). Washington DC: American Psychological Association.

Birt, C. M. \& Dion, K. L. (1987). Relative deprivation theory and responses to discrimination in a gay male and lesbian sample. British Journal of Social Psychology, 26 , 139-145.

Bowles, G. \& Duelli Klein, R. (1983). Theories of women's studies . London: Routledge.

Browne, M. W., \& Cudeck, R. (1993). Alternative ways of assessing model fit. In K. A. Bollen \& J. S. Long (Eds.), Testing structural equation models (pp. 136-162). Newbury Park, CA: Sage.

Bruner, J. S. (1957). On perceptual readiness. Psychological Review, $\underline{64}$, 123-151. 
Byrne, B. M. (1989). A primer of LISREL: Basic applications and programming for confirmatory factor analytic models. New York: SpringerVerlag.

Byrne, B. M. (1991). The Maslach Burnout Inventory: Validating factorial structure and invariance across intermediate, secondary and university educators. Multivariate Behavioral Research, 26, 583-605.

Byrne, B. M. (1994). Structural equation modeling with EQS and $\underline{\text { EQS/Windows }}$. Thousand Oaks: Sage.

Campbell, D. T. (1958). Common fate, similarities and other indices of the status of aggregates of persons as social entities. Behavioural Science, $\underline{3}, 14-$ 25.

Carey, P. (1980). Personal is political. Canadian Women's Studies, $\underline{2}$, 4-7.

Chaiken, S. \& Baldwin, M. W. (1981). Affective-cognitive consistency and the effect of salient behavioral information on the self-perception of attitudes. Journal of Personality and Social Psychology, 41, 1-12.

Crosby, F. J. (1982). Relative deprivation and working women . New York: Oxford University Press.

Crosby, F. J. (1984). The denial of personal discrimination. American Behavioral Scientist, 27, 371-386.

Crosby, F. J., Clayton, S., Alksnis, O. \& Hemker, K. (1986). Cognitive biases in the perceptions of discrimination: The importance of format. $\underline{\text { Sex }}$ Roles $, \underline{14}, 637-646$.

Crosby, F. J., Pufall, A., Snyder, R., O'Connell, M. \& Whalen, P. (1989). The denial of personal disadvantage among you, me, and all the other ostriches. In M. Crawford \& M. Gentry (Eds.), Gender and thought (pp. 7999). New York: Springer-Verlag.

D'Emilio, J. (1983). Sexual politics, sexual communities: The making of a homosexual minority in the U.S., 1940-1970 . Chicago: University of Chicago 
Press.

Dion, K. L., \& Kawakami, K. (1996). Ethnicity and perceived discrimination in Toronto: Another look at the personal/group discrimination discrepancy. Canadian Journal of Behavioural Science, $\underline{28}, 203-213$.

Driefus, C. (1973). Women's fate: Rap from a feminist consciousnessraising_group. New York: Bantam.

Foster, M. D. (1995). Dimensions of discrimination: What women think is important . Unpublished manuscript, Carleton University, Ottawa.

Foster, M. D., \& Matheson, K. (1995). Double relative deprivation: Combining the personal and political. Personality and Social Psychology Bulletin, 21, 1167-1177.

Foster, M. D., \& Matheson, K. (in press). Perceiving and feeling personal discrimination: Motivation or inhibition for collective action? Group Processes and Intergroup Relations.

Friedman, D. \& McAdam, D. (1992). Networks, choices and the life of a social movement. In A. D. Morris \& C. McClurg Mueller (Eds.), Frontiers in Social Movement Theory. (pp.156-173). New Haven: Yale University Press.

Gamson, W. A. (1992). The social psychology of collective action. In A. D. Morris \& C. McClurg Mueller (Eds.), Frontiers in Social Movement Theory (pp. 53-76). New Haven: Yale University Press.

Guimond, S. \& Dubé-Simard, L. (1983). Relative deprivation theory and the Quebec nationalist movement: The cognitive-emotion distinction and the personal-group deprivation issue. Journal of Personality and Social Psychology , 44 , 526-535.

Hafer, C. L. \& Olson, J. M. (1993). Beliefs in a just world, discontent and assertive actions by working women. Personality and Social Psychology. Bulletin, $\underline{19}, 30-38$. 
Hogg, M. A., \& Turner, J. C. (1987). Intergroup behaviour, selfstereotyping and the salience of social categories. British Journal of Social Psychology, $\underline{26}, 325-340$.

Hoyle, R. H. \& Panter, A. T. (1995). Writing about structural equation models. In R. H. Hoyle (Ed.), Structural equation modeling: Concepts, issues and applications (pp. 158-176). Structural equation modeling: Concepts, issues and applications (pp. 76-99). Thousand Oaks, CA: Sage.

Hu, L. \& Bentler, P. M. (1995). Evaluating model fit. Thousand Oaks, CA: Sage. In R. H. Hoyle (Ed.), Structural equation modeling: Concepts, issues and applications (pp. 76-99). Thousand Oaks, CA: Sage.

Jensen, I. W \& Gutek, B. A. (1982). Attributions and assignment of responsibility in sexual harassment. $\underline{\text { Journal of Social Issues }}, \underline{38}, 121-136$.

Kawakami, K., \& Dion, K. L. (1993). The impact of salient self-identities on relative deprivation and action intentions. European Journal of Social Psychology, $\underline{23}, 525-540$.

Kohlberg, L. (1963). Development of children's orientation toward a moral order. Vita Humana , $\underline{6}, 11-36$.

Lalonde, R. N., \& Cameron, J. E. (1993). Behavioral responses to discrimination: The focus on action. In M. P. Zanna \& J. M. Olson (Eds.), The psychology of prejudice: The Ontario Symposium (Vol. 7, pp. 257-288). Hillsdale, NJ: Erlbaum.

Lee, Y. T. (1992). Ingroup preference and similarities among African American and Chinese American Studies. Journal of Social Psychology, 133 (2), 225-235.

MacCallum, R. B., Browne, M. W., \& Sugawara, H. M. (1996). Power analysis and determination of sample size for covariance structure modeling. Psychological Methods, 1 (2), 130-149.

Moghaddam, F. M., Stolkin, A. J., \& Hutcheson, L. S. (1997). A 
generalized personal/group discrepancy: Testing the domain specificity of a perceived higher effect of events on one's group than on oneself. Personality and Social Psychology_Bulletin, 23 (7), 743-750.

Mulaik, S. A., James, L. R., Van Alstine, J., Bennett, N., Lind, S., \& Stilwell, C. D. (1989). An evaluation of goodness of fit indices for structural equation models. Psychological Bulletin, $\underline{105}, 430-445$.

Neto, F (1995). Knowledge of sex stereotypes and internality. Psychological Reports, $\underline{76}$, 504-506.

Oakes, P. J. \& Turner, J. C. (1990). Is limited information processing capacity the cause of social stereotyping? In W. Stroeb \& M. Hewstone (Eds.), European Review of Social Psychology: Vol. 1 . (pp. 111-131). Chichester, England: John Wiley \& Sons.

Porter, L. E. \& Taylor, D. M. (1992). The personal/group discrimination: The role of social identity. Paper presented at the Annual Convention of the Canadian Psychological Association, Quebec, Canada.

Rosch, E. (1978). Principles of categorization. In E. Rosch \& B. B. Lloyd (Eds.), Cognition and categorization. Hillsdale, NJ: Erlbaum.

Ruggiero, K. M. \& Taylor, D. M. (1994). The personal/group discrimination discrepancy: Women talk about their experiences. Applied Social Psychology,_24, 1806-1826.

Ruggiero, K. M., \& Taylor, D. M. (1995). Coping with discrimination: How disadvantaged group members perceive the discrimination that confronts them. Journal of Personality and Social Psychology, 68 , 826-838.

Seligman, M. E. P. (1975). Helplessness: On depression, development and death. San Francisco: Freeman.

Smith, E. R. \& Henry, S. (1996). An in-group becomes part of the self: Response time evidence. Personality and Social Psychology Bulletin, 22 (6), 635-642. 
Stanley, L. \& Wise, S. (1983). Breaking out: Feminist consciousness and feminist research. London: Routledge \& Kegan Paul.

Stephan, W. G. (1977). Cognitive differentiation in intergroup perception. Sociometry , $\underline{40}, 50-58$.

Tajfel, H. (1969). Cognitive aspects of prejudice. Journal of Social experiences $, \underline{15}(4), 79-97$.

Taylor, D. M., Wright, S. C., Moghaddam, F. M. \& Lalonde, R.N. (1990). The personal/group discrimination discrepancy: Perceiving my group, but not myself to be a target for discrimination. Personality and Social Psychology. Bulletin, $\underline{16}, 254-262$.

Taylor, D. M., Wright, S. C., \& Porter, L. E. (1994). Dimensions of perceived discrimination: The personal/group discrimination discrepancy. In M. P. Zanna \& J. M. Olson (Eds.), The Psychology of Prejudice: The Ontario Symposium (Vol 7, pp. 233-255). Hillsdale, NJ: Lawrence Erlbaum.

Turner, J. C., Hogg, M. A., Oakes, P. J., Reicher, S. D. \& Wetherell, M. S. (1987). Rediscovering the social group: A theory of self-categorization. New York: Basil Blackwell Inc.

Turner, J. C., \& Oakes, P. J. (1986). The significance of the social identity concept for social psychology with reference to individualism, interactionism, and social influence. British Journal of Social Psychology, 25, 237-252.

Turner, J. C. \& Oakes, P. J. (1989). Self-categorization theory and social influence. In P. B. Paulus (Ed). The psychology of group influence. Hillsdale, N.J.: Erlbaum.

Turner, J. C., Oakes, P. J. Haslam, A., \& McGarty, C. (1994). Self and collective: Cognition and social context. Personality and Social Psychology Bulletin, $\underline{20}, 454-463$.

Walker, I., \& Mann, L. (1987). Unemployment, relative deprivation and social protest. Personality and Social Psychology_Bulletin, 13, 275-283. 
Walker, I., \& Pettigrew, T. F. (1984). Relative deprivation theory: An overview and conceptual critique. British Journal of Social Psychology, $\underline{23}$, 301-310.

Wilkinson, N. \& Schneider, M. (1990). The development of a feminist consciousness in women: work in progress. Paper presented at the Canadian Psychological Association Annual Conference, Ottawa, Canada.

Wright, S. C., Taylor, D. M., \& Moghaddam, F. M. (1990). Responding to membership in a disadvantaged group: From acceptance to collective protest. Journal of Personality and Social Psychology, $\underline{58}$, 994-1003.

Table 1

Descriptive statistics for variables in the model

Variables $\quad$ M SD Confidence Interval

Meta-contrast ratios along social experiences

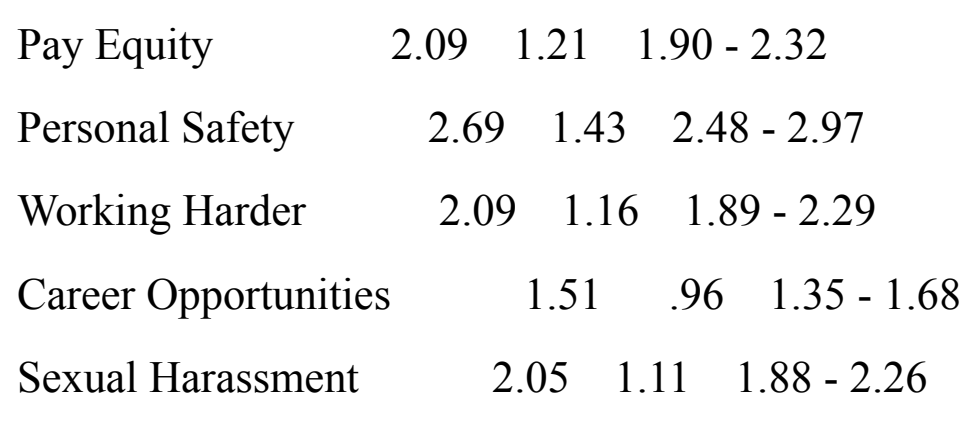

Meta-contrast ratios along stereotypes

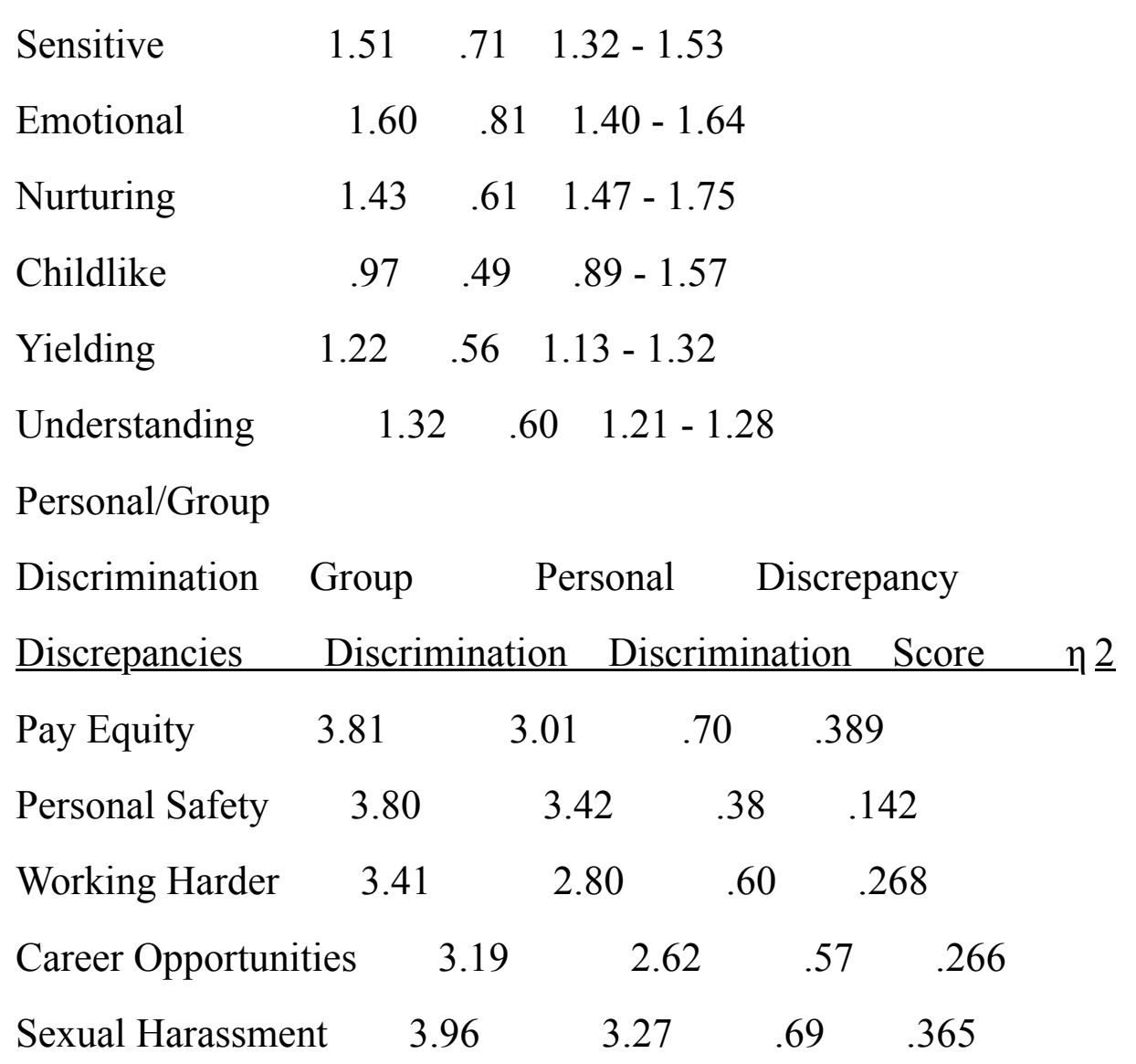


Note: Group and personal discrimination $\mathrm{t}$-scores differed at $\mathrm{p}<.05$

Table 2

Summary of Test Statistics for Measurement and Full Structural Model

Measurement Models

(Confirmatory Factor Analyses).

$\underline{\mathrm{X}} \underline{2}$ df residuals $\mathrm{CFI}$ PCFI RMSEA $\underline{\mathrm{CI}}$

$\begin{array}{llllllll}\text { Social experiences } & 5.11 \mathrm{a} & 5 & .04 & .99 & .50 & .04 & .00-.14\end{array}$

Stereotypes

8.04 a $\quad 9 \quad .05$

$\begin{array}{llll}.99 & .60 & .09 & .02-.15\end{array}$

Personal/Group

Discrimination

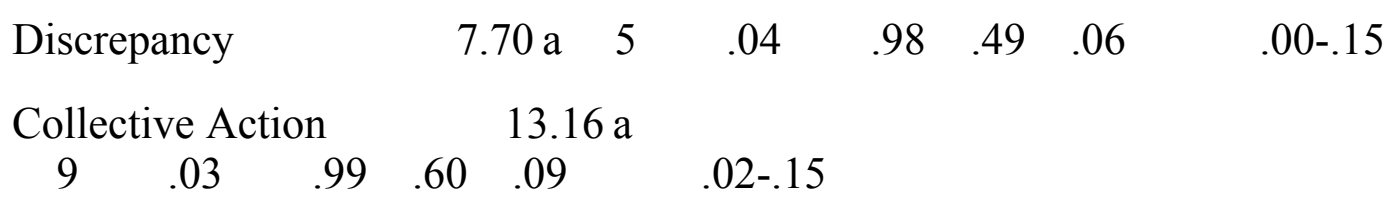

Full Model

$$
\begin{array}{lllllll}
262.33 & 205 & .07 & .92 & .82 & .06 & .05-.08
\end{array}
$$

Note: a refers to a X $2>.05$, indicating that there are no significant differences between the hypothesized and observed data.

Figure Caption

Figure 1. Structural model of the relationships between meta-contrast ratios, personal/group discrimination discrepancy, and collective actions. 